\section{HOW TO DRAW A STRAIGHT LINE'}

II.

T Fig. 6, QC is the extra link pivoted to the fixed point $Q$, the other pivot on it $C$, describing the circle $O \mathrm{CR}$. The straight lines $\mathrm{P} M$ and $\mathrm{P}^{\prime} \mathrm{M}^{\prime}$ are supposed to be perpendicular to $\mathrm{M} \mathrm{R} \mathrm{Q} \mathrm{O} \mathrm{M'.}$

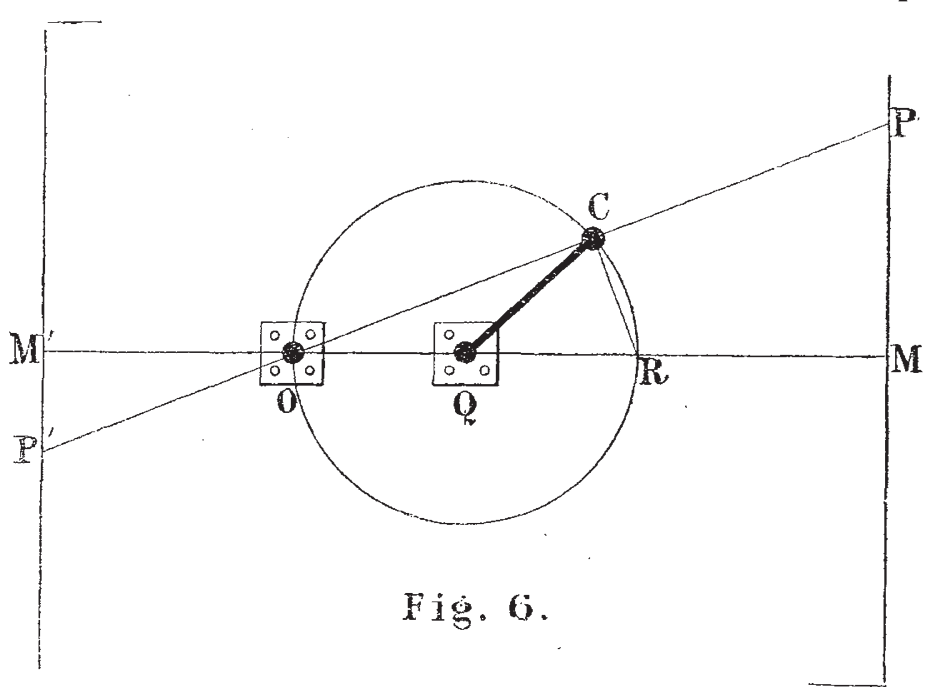

$$
\begin{aligned}
\mathrm{OA}^{2}-\mathrm{AP} & =\mathrm{O} n^{2}-\mathrm{P} n^{2} \\
& =[\mathrm{O} n-\mathrm{P} n] \cdot[\mathrm{O} n+\mathrm{P} n] \\
& =\mathrm{OC} \cdot \mathrm{OP} .
\end{aligned}
$$

Thus since $\mathrm{OA}$ and $\mathrm{AP}$ are both constant $\mathrm{OC} \cdot \mathrm{OP}$ is always constant, however far or near $C$ and $P$ may be to $O$. If then the pivot $O$ be fixed to the point $O$ in Fig. 6 , and the pivot $C$ be made to describe the circle in the figure by being pivoted to the end of the extra link, the pivot $\mathrm{P}$ will satisfy all the conditions necessary to make it move in a straight line, and if a pencil be fixed at $\mathrm{P}$ it will draw a straight line. The distance of the line from the fixed pivots will of course depend on the magnitude of the quantity $O A^{2}-O P^{2}$ which may be varied at pleasure.

I hope you clearly understand the two elements composing the apparatus, the extra link and the cell, and the part each plays, as I now wish to describe to you some modifications of the cell. The extra link will remain the same as before, and it is only the cell which will undergo alteration.

If I take the two linkages in Fig. 8, which are known as the "kite" and the "spearhead," and place one on the other so that the long links of the one coincide with those of the other, and then amalgamate the coincident long links together, we shall get the original cell of Figs. 5 and 7 . If then we keep the angles between the long links, or that between the short links, the same in the

Now the angle OCR, being the angle in a semicircle, is a right angle. Therefore the triangles $\mathrm{OCR}, \mathrm{OM} \mathrm{P}$ are similar. Therefore,

Therefore,

$$
\text { OC : OR : : O }: \text { : P. }
$$

$$
\mathrm{OC} \cdot \mathrm{OP}=\mathrm{OM} \cdot \mathrm{OR} \text {. }
$$

wherever $\mathrm{C}$ may be on the circle. That is, since $\mathrm{O} M$ and $O R$ are both constant, if while $C$ mores in a circle $\mathrm{P}$ moves so that $\mathrm{O}, \mathrm{C}, \mathrm{P}$ are always in the same straight line, and so that $O C \cdot O P$ is always constant; then $P$ will describe the straight line $\mathrm{PM}$ perpendicular to the line $O Q$.

It is also clear that if we take the point $P^{\prime}$ on the other side of $\mathrm{O}$, and if $\mathrm{OC} \cdot \mathrm{OP}^{\prime}$ is constant $\mathrm{P}^{\prime}$ will describe

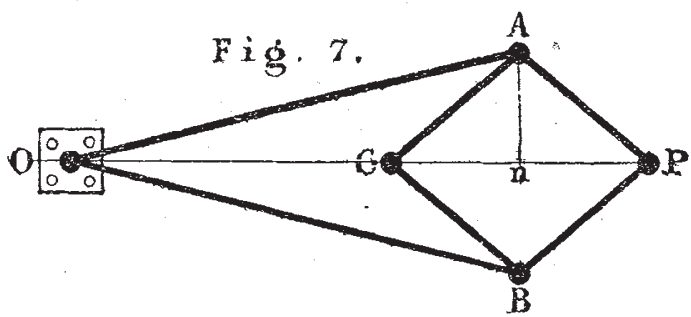

the straight line $\mathrm{P}^{\prime} \mathrm{M}^{\prime}$. This will be seen presently to be important.

Now, turning to Fig. 7, which is a skeleton drawing of the Peaucellier cell, we see that from the symmetry of the construction of the cell, $\mathrm{O}, \mathrm{C}, \mathrm{P}$, all lie in the same straight line, and if the straight line $\mathrm{A} n$ be drawn perpendicular to $\mathrm{C} \mathrm{P}$-it must still be an imaginary one, as we have not proved yet that our apparatus does draw a straight line $-\mathrm{C} n$ is equal to $n \mathrm{P}$.

Now,

$$
\mathrm{O} \mathrm{A}^{2}=\mathrm{O} n^{2}+\mathrm{A} n^{2}
$$

therefore,

$$
\mathrm{AP} \mathrm{P}^{2}=\mathrm{P} n^{2}+\mathrm{A} n^{2}
$$

1 Lecrure at South Kensington in connection with the Loan Collection of Scientific Apparatus, by A. B. Kempe, B.A. Continued from p. 67. "kite" and "spear-bead," we see that the height of the "kite" multiplied by that of the "spear-head" is con. stant.

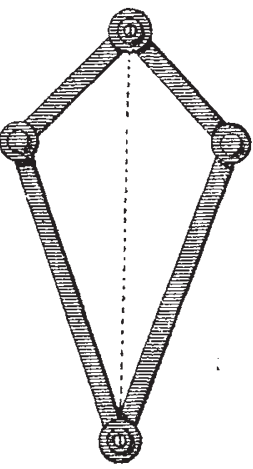

Fig. 8.

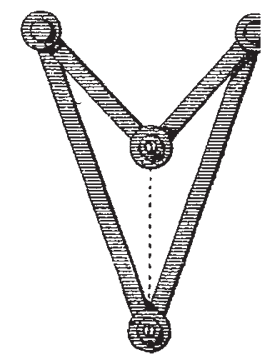

Let us now, instead of amalgamating the long links of the two linkages, amalgamate the short ones. We then get the linkage of Fig. 9; and if the pivot where the short links meet is fixed, and one of the other free pivots be

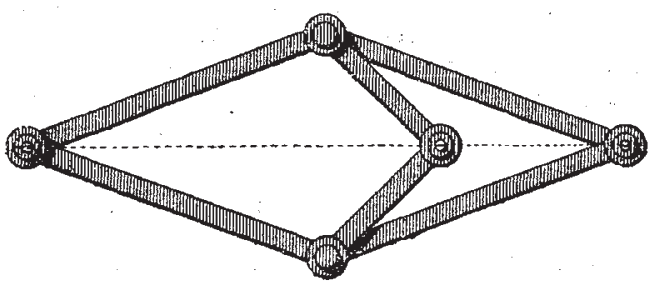

Fig. 9.

made to move in the circle of Fig. 6 by the extra link, the other will describe, not the straight line $\mathrm{PM}$, but the straight line $\mathrm{P}^{\prime} \mathrm{M}^{\prime}$. In this form, which is a very compact one, the motion has been applied in a beautiful manner 
to the air engines which are employed to ventilate the Houses of Parliament. The ease of working and absence of friction and noise is very remarkable. The engines were constructed and the Peaucellier apparatus adapted to them by Mr. Prim, the engineer to the Houses, by whose courtesy I have been enabled to see them, and I can assure you that they well worth a visit.

Another modification of the cell is shown in Fig. 10. If instead of employing a "kite" and "spear-head" of

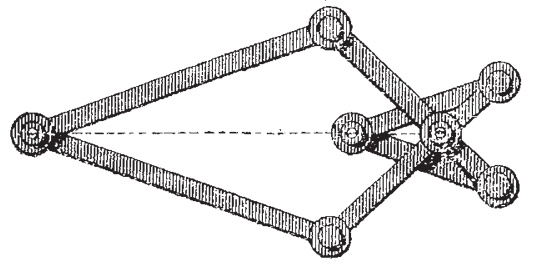

$\mathrm{F}$ ig. 10 .

the same dimensions I take the same "kite" as before but use a "spear head" of half the size of the former one, the angles being, however, kept the same, the product of the heights of the two figures will be half what it was before, but still constant. Now instead of superimposing the links of one figure on the other, it will be seen that in Fig. Io I fasten the shorter links of each figure together end to end. Then as in the former cases, it I fix the pivot at the point where the links are fixed together, I get

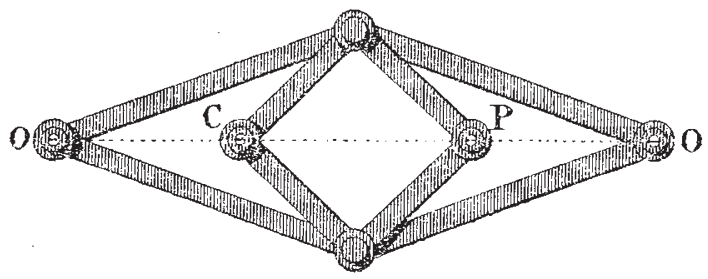

Fig. 11 .

a cell which may be used by the employment of an extra link, to describe a straight line. A model employing this form of cell is exhibited in the Loan Collection by the Conservatoire des Arts et Métiers of Paris, and is of exquisite workmanship; the pencil seems to swim along the straight line.

M. Peaucellier's discovery was introduced into England by Prof. Sylvester in a lecture he delivered at the Royal Institution in January, 1874 , which excited very great in-

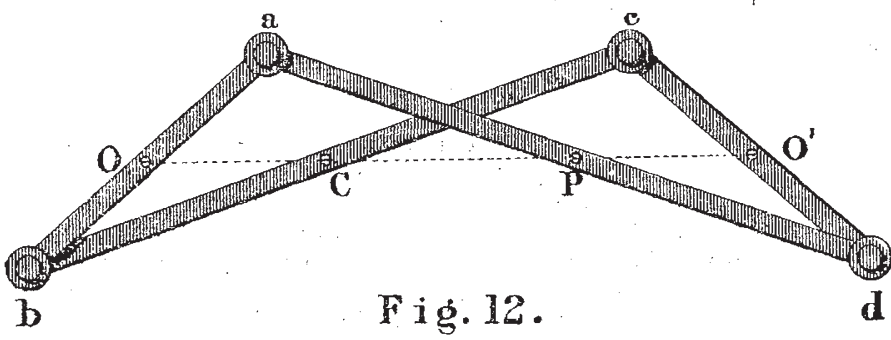

terest and was the commencement of the consideration of the subject of linkages in this country.

In August of the same year Mr. Hart, of Woolwich Academy, read a paper at the British Association meeting, in which he showed that M. Peaucellier's cell could be replaced by an apparatus containing only four links instead of six. The new linkage is arrived at thus.

If to the ordinary Peaucellier cell I add two fresh links of the same length as the long ones I get the double, or tances between the pivots in the same proportion, those four points had exactly the same properties as the four points of the double cell. That the four points always lie in a straight line is seen thus : considering the triangle $a b d$, since $a \mathrm{O}: \mathrm{O} b:: a \mathrm{P}: \mathrm{P} d$ therefore $\mathrm{OP}$ is parallel to $b d$ and the perpendicular distance between the parallels is to the height of the triangle $a b d$ as $\mathrm{O} b$ is to $a b$; the same reasoning applies to the straight line $\mathrm{CO}^{\prime}$, and since $a b: \mathrm{O} b:: c d: \mathrm{O}^{\prime} d$ and the heights of the triangles $a b d, c b d$, are clearly the same, therefore the distances of $\mathrm{OP}$ and $\mathrm{O}^{\prime} \mathrm{C}$ from $b d$ are the same, and $\mathrm{O} \mathrm{C} \mathrm{P} \mathrm{O}^{\prime}$ lie in the same straight line.

d That the product OC:OP is constant appears at once when it is seen that $O b C$ is half

rather quadruple cell, for it may be used in four different ways, shown in Fig. II. Now Mr. Hart found that if he
took an ordinary parallelogramatic linkwork in which the

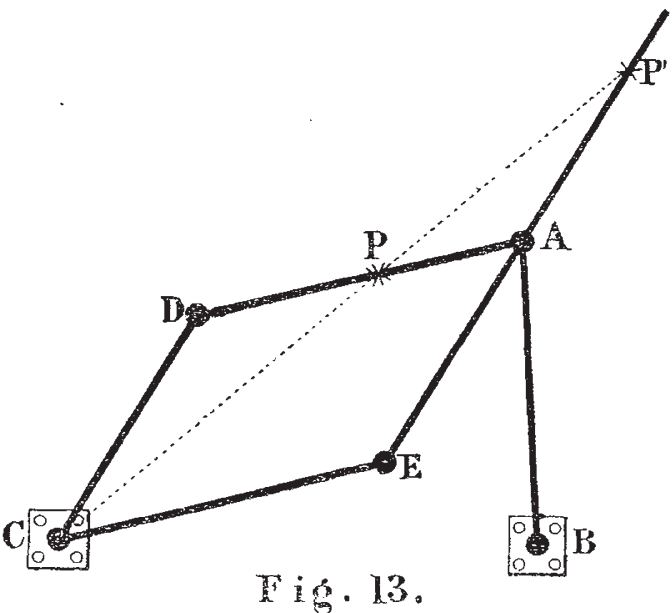

adjacent sides are unequal, and crossed the links so as to form what is called a contra-parallelogram, Fig. 12, and

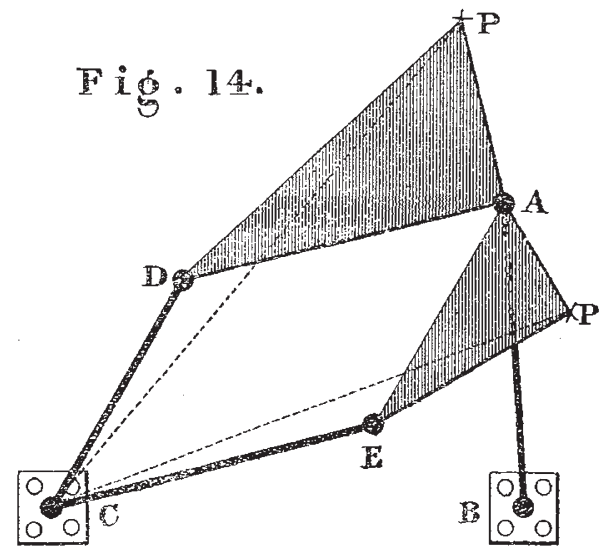
a "spear head" and O $a$ P half a "kite;" similarly it may be shown that $\mathrm{O}^{\prime} \mathrm{P} \cdot \mathrm{O}^{\prime} \mathrm{C}$ is constant, as also $\mathrm{OC} \cdot \mathrm{CO}^{\prime}$ and $\mathrm{OP} \cdot \mathrm{P} \mathrm{O}^{\prime}$. Employing then the Hart's cell as we employed Peaucellier's, we get a five-link straight line motion. A model of this is exhibited in the Loan Collection by M. Breguet.

I now wish to call your attention to an extension of Mr. Hart's apparatus, which was discovered simultaneously by Prof. Sylvester and myself. In Mr. Hart's 
apparatus we were only concerned with bars and points on those bars, but in the apparatus I wish to bring before you we have pieces instead of bars. I think it will be more interesting if I lead up to this apparatus by detailing to you its history, especially as I shall thereby be enabled to bring before you another very elegant and very important linkage-the discovery of Prof. Sylvester.

When considering the problem presented by the ordi-

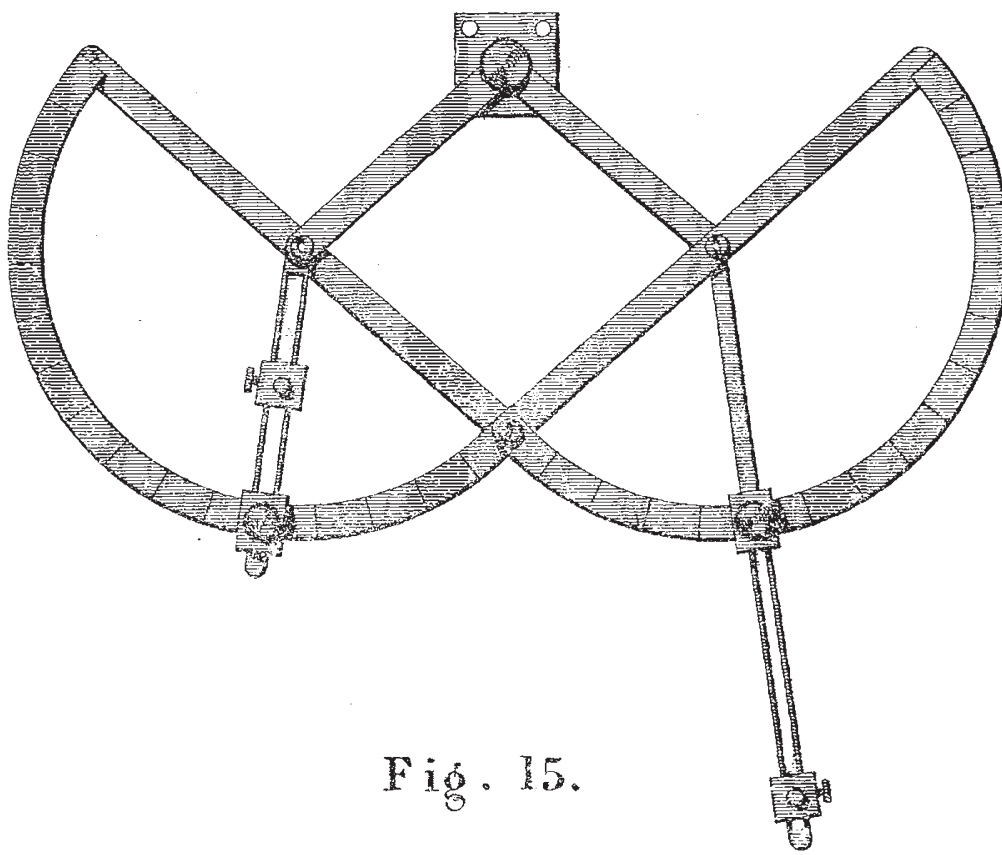

equal to $\mathrm{CD}$. $\mathrm{CDAE}$ is then a parallelogram, and if an imaginary line $C \mathrm{P} \mathrm{P}^{\prime}$ be drawn, cutting $\mathrm{E} A$ producd in $P^{\prime}$ it will at once be seen that $P^{\prime}$ is a fixed point on $\mathrm{E} A$ produced, and $\mathrm{C}^{\prime}$ bears always a fixed proportion to $\mathrm{CP}$, viz., $\mathrm{CD}: \mathrm{CE}$. Thus the curve described by $\mathrm{P}^{\prime}$ is precisely the same as that described by $P$, only it is larger in the proportion CE:CD. Thus if we take away the bars $C D$ and $D A$, we shall get a three-bar linkwork, describing precisely the same curves, only of different magnitude, as our first three-bar motion described, and this new three-bar linkwork is the same as the old with the radial link $\mathrm{CD}$ and the traversing link $\mathrm{DA}$ interchanged.

On my communicating this result to Prof. Sylvester, he at once saw that the property was one not confined to the particular case of points lying on the traversing bar, in fact to three-bar motion, but was possessed by threepiece motion. In Fig. $14 \mathrm{CD} A \mathrm{~B}$ is a three-bar motion, as in Fig. I3, but the tracing point or "graph" does not lie on the line joining the joints $A D$, but is anywhere else on a "piece" on which the joints A D lie. Now, as before, add the bar $\mathrm{CE}, \mathrm{CE}$ being equal to $\mathrm{A} \mathrm{D}$, and the piece $\mathrm{AE} \mathrm{P} \mathrm{P}^{\prime}$, making $\mathrm{AE}$ equal to $\mathrm{CD}$, and the triangle $A E P^{\prime}$ similar to the triangle $\mathrm{PDA}$; so that the angles $\mathrm{AEP}$, A D $P$ are equal, and

$$
\mathrm{P}^{\prime} \mathrm{E}: \mathrm{EA}:: \mathrm{AD}: \mathrm{DP} \text {. }
$$

It follows easily from this-you can work it out for yourselves without diffculty-that the ratio $\mathrm{P}^{\prime} \mathrm{C}: \mathrm{PC}$ is constant and the angle $\mathrm{PC} \mathrm{P}^{\prime}$ is constant;

nary three- $b$ ar motion consisting of two radial bars and a traversing bar, it occurred to me-I do not know how or why, it is often very difficult to go back and find whence one's ideas originate - to consider the relation between the curves described by the points on the traversing bar in any given three-bar motion, and those described by the points on a similar three-bar motion, but in which the traversing bar and one of the radial bars had been made

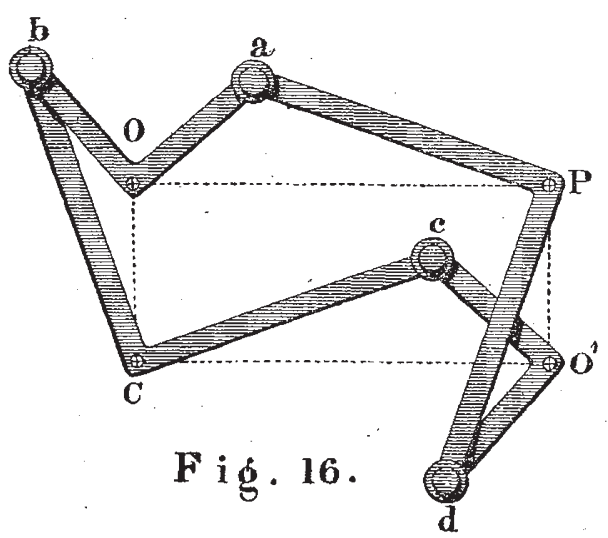

to change places. The proposition was no sooner stated than the solution became obvious; the curves were precisely similar. In Fig. 13 let $C D$ and $B A$ be the two radial bars turning about the fixed centres $C$ and $B$, and let $\mathrm{D} A$ be the traversing bar, and let $\mathrm{P}$ be any point on it describing a curve depending on the lengths of $A B$, $B C, C D$, and DA. Now add to the three-bar motion the bars $C E$ and $E A P^{\prime}, C E$ being equal to $D A$, and $E A$ thus the paths of $\mathrm{P}$ and $\mathrm{P}$ ", or the "grams" described by the "graphs," $\mathrm{P}$ and $\mathrm{P}$ " are similar, only they are of different sizes, and one is turned through an angle with respect to the other.

Now you will observe that the two proofs I have given are quite independent of the bar $\mathrm{AB}$, which only affects the particular curve described by $\mathrm{P}$ and $\mathrm{P}^{\prime}$. If we get rid of $A B$, in both cases we shall get in the first figure the ordinary pantagraph, and in the second a beautiful extension of it called by Prof. Sylvester, its inventor, the Plagiograph or Skew Pantagraph. Like the pantagraph, it will enlarge or reduce figures, but it will do more, it will turn them through any required angle, for by properly choosing the position of $\mathrm{P}$ and $\mathrm{P}^{\prime}$, the ratio of $C P^{\prime}$ to $C P^{\prime}$ can be made what we please, and also the angle $\mathrm{PCP}^{\prime}$ can be made to have any required value. If the angle $\mathrm{PCP}^{\prime}$ is made equal to o or $180^{\circ}$, we get the two forms of the pantagraph now in common use; if it be made to assume successively any value which is a submultiple of $360^{\circ}$, we can, by passing the point $\mathrm{P}$ each time over the same pattern, make the point $\mathrm{P}^{\prime}$ reproduce it round the fixed centre $\mathrm{C}$ after the fashion of a kaleidoscope. I think you will see from this that the instrument, which has, as far as I know, never been practically constructed, deserves to be put into the hands of the designer. I give here a picture of a little model of a possible form for the instrument furnished by me to the Loan Collection by request of Prof. Sylvester.

After this discovery of Prof. Sylvester it occurred to him and to me simultaneously-our letters announcing our discovery to each other crossing in the post-that the principle of the plagiograph might be extended to $\mathrm{Mr}$. Hart's contra-paralielogram; and this discovery I shall now proceed to explain to you. I shall, however, be more easily able to do so by approaching it in a different manner to that in which I did when I discovered it. 
If we take the contra-parallelogram of Mr. Hart and bend the links at the four points which lie on the same straight line, or foci, as they are sometimes termed, through the same angle, the four points, instead of lying in the same straight line, will lie at the four angular points of a parallelogram of constant angles - two the angle that the bars are bent through, and the other two their supplements-and of constant area, so that the product of two adjacent sides is constant.

In Fig. 16 the lettering is preserved as in Fig. 12 , so that the way in which the apparatus is formed may be at once seen. The holes are taken in the middle of the links and the bending is through a right angle. The four holes $\mathrm{OPO}^{\prime} \mathrm{C}$ lie at the four corners of a right-angled parallelogram, and the product of any two adjacent sides, as for example $\mathrm{OC} \cdot \mathrm{OP}$, is constant. It follows that if $O$ be pivoted to the fixed point $O$ in Fig. 16 , and $C$ be pivoted to the extremity of the extra link, $P$ will describe a straight line, not $\mathrm{PM}$, but one inclined to $\mathrm{P} M$ at an angle the same as the bars, are bent through, i.e., a right angle. Thus the straight line will be parallel to the line joining the fixed pivots $\mathrm{O}$ and $\mathrm{Q}$. This apparatus, which for simplicity I have described as formed of four straight links which are afterwards bent, is of course strictly speaking, formed of four plane links, such as those employed in Fig. I, on which the various points are taken. This explains the name given to it by Prof. Sylvester, the "Quadruplane." Its properties are not difficult to investigate, and when I point out to you that in Fig. 16 as in Fig. 1 2, $\mathrm{O} b, b \mathrm{C}$ form half a "spear-head," and $\mathrm{O} a, a \mathrm{P}$ half a "kite," you will very soon get to the bottom of it.

I cannot leave this apparatus in which my name is associated with that of Prof. Sylvester without expressing my deep gratitude for the kind interest which he took in my researches, and my regret that his departure for America to undertake the post of Professor in the new Johns Hopkins University has deprived me of one whose valuable suggestions and encouragement helped me much in my investigations.

(To be continued.)

\section{METEOROLOGICAL NOTES}

NOTES OF THE WEATHER IN SCOTLAND, FARÖ, AND ICELAND.- It appears from the meteorological returns for the eight principal towns in Scotland, that the weather of last April has been distinguished by low temperature, $3 \%$ under the average, great fluctuations in the barometric pressure, large rainfall distributed among the towns with unusual uniformity, much wind and that more persistently from the eastward than has been before chronicled for any month of any year since the Scottish Meteorological Society was founded. At the monthly meeting of the Edinburgh Botanical Society, held on Thursday, May Io, Mr. McNab stated that the present spring is later than any other during the last twenty-eight years, when systematic observations on the flowering of plants began to be made in the Royal Botanic Garden of Edinburgh. In Farö the winter and early spring have been among the worst ever known, high easterly and northerly winds and snowstorms being very prevalent. In March and April snow fell on no fewer than thirty-one days. The mean barometric pressure at $32^{\circ}$ and sea-level at Thorshavn during April, was 29,945 inches. On the other hand the winter, until Easter, was one of the finest ever known in Iceland, particularly in the north of the island. There was little snow, any frost that occurred was of short continuance, and fine calm weather prevailed. But about Easter-day a series of northerly snowstorms began, accompanied by severe frosts, which lasted with little intermission for about a week, causing the loss of many ships, and snowing up the pastures. Since these storms sunshine prevailed up to May 6 . When the steamer left Reykjavik the Greenland and Spitzbergen ice had appeared off the northern coasts about the middle of March, but only stray icebergs neared the land, the ice becoming "land-fast" nowhere in any quantity. The season has also been singularly mild in Canada. Spring set in there fully three weeks earlier than usual, and as very little rain had fallen up to the close of April and the thaw was very gentle, the rivers were unusually low for the time of the year.

METEOROLOGY OF HOLLAND.-A highly-important work on the annual march of the thermometer and barometer in Holland, deduced from observations made from 1843 to 1875 , has been published by Dr. Buys Ballot, the distinguished director of the meteorological system of that country. The monthly means for each meteorological lustrum of five years, as well as for the whole period during which the observations have been made, are given for each of the hours of observations. From these general averages, the normal values for each of the ten stations have been determined by the process of differentiation, so that the normals are substantially the averages which would have been obtained if the observations at each of the stations had been made during precisely the same terms of years. The normals are calculated for very extended periods by a comparison of the results arrived at for the Dutch stations, with the long averages for Copenhagen, Paris, and Greenwich. Thermometric and barometric normals have also been determined for each day of the year for all the stations, which cannot but prove to be of considerable value in framing forecasts of the weather and in some other practical matters. We hope, however, that Dr. Buys Ballot may be enabled soon to calculate the arithmetic means of the temperature of each day of the year at all his stations, and thus complete what must be regarded as an able and exhaustive discussion of the two most important elements of the meteorology of Holland. Tables are also added, showing the mean temperature of each month during the whole period of observations, and an exceedingly valuable table of the monthly mean barometric measure at Maestricht for sixty-nine years, beginning with 1807 and ending with 1875.

TyCho BRAHE'S METEOROLOGICAL JOURNAL.-The Royal Academy of Sciences and Letters of Copenhagen has laid scientific men generally under a debt of gratitude in publishing in extenso, the Meteorological Journal, kept at Uraniborg in the Isle of Hveen by Tycho Brahe from I 582 to I597. To the journal is appended a clear and interesting résumé of the observations by $M$. Paul la Cour. The results of the observations made on clouds, rain, snow, hail, fog, winds, frost, thunder, halos, and auroras, by the celebrated astronomer nearly 300 years ago, are compared with similar observations made at Copenhagen and other stations in Denmark in recent years. The results of the different sets of observations are fairly accordant when the different positions and times of observing are taken into consideration.' The most noteworthy difference is in the monthly curve of thunder, the maximum at Hveen being strongly pronounced in June, whereas the recent observations at fourteen stations in different parts of Denmark have the maximum extending equally over June, July, and August -a difference perhaps due to a different seasonal distribution of thunder in different parts of Denmark. Of the seventy-eight auroras which were noted by Tycho Brahe, seventy-six occurred during the ten years from I $582-1591$, and only two during the six years immediately following. From the detailed descriptions given of certain auroras and auroral arches, M. Paul la Cour concludes that the magnetic inclination at this observatory during 1584 was somewhere between $72^{\circ} 25^{\prime}$, and $73^{\circ} 25^{\prime}$.

"Atlas MÉtéorologique" of the ObServatoy of PARIS, I 875.-A rapid glance through the Atlas Météoro- 